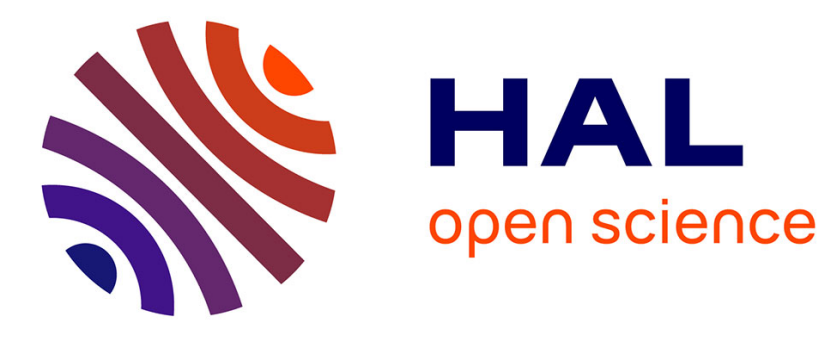

\title{
Ultrafast Acoustic Vibrations of Bimetallic Nanoparticles
}

\author{
Tatjana Stoll, Paolo Maioli, Aurélien Crut, Julien Burgin, Pierre Langot, \\ Michel Pellarin, Ana Sánchez-Iglesias, Benito Rodríguez-González, Luis M. \\ Liz-Marzán, Natalia del Fatti, et al.
}

\section{To cite this version:}

Tatjana Stoll, Paolo Maioli, Aurélien Crut, Julien Burgin, Pierre Langot, et al.. Ultrafast Acoustic Vibrations of Bimetallic Nanoparticles. Journal of Physical Chemistry C, 2015, 119 (3), pp.1591-1599. 10.1021/jp511070h . hal-01115164

\author{
HAL Id: hal-01115164 \\ https://hal.science/hal-01115164
}

Submitted on 21 Feb 2018

HAL is a multi-disciplinary open access archive for the deposit and dissemination of scientific research documents, whether they are published or not. The documents may come from teaching and research institutions in France or abroad, or from public or private research centers.
L'archive ouverte pluridisciplinaire HAL, est destinée au dépôt et à la diffusion de documents scientifiques de niveau recherche, publiés ou non, émanant des établissements d'enseignement et de recherche français ou étrangers, des laboratoires publics ou privés.

\section{()(1)(2)}

Distributed under a Creative Commons Attribution - ShareAlikel 4.0 International 


\title{
Ultrafast Acoustic Vibrations of Bimetallic Nanoparticles
}

Tatjana Stoll, ${ }^{\dagger}$ Paolo Maioli, ${ }^{*}{ }^{\dagger}$ Aurélien Crut, ${ }^{\dagger}$ Julien Burgin, ${ }^{\ddagger}$ Pierre Langot, ${ }^{\ddagger}$ Michel Pellarin, ${ }^{\dagger}$ Ana Sánchez-Iglesias, ${ }^{\S}$ Benito Rodríguez-González, ${ }^{\|}$Luis M. Liz-Marzán, ${ }^{\S, i, \perp}$ Natalia Del Fatti, ${ }^{\dagger}$ and Fabrice Vallée ${ }^{\dagger}$

\author{
${ }^{\dagger}$ Institut Lumière Matière, UMR5306 Université Lyon 1-CNRS, 69622 Villeurbanne cedex, France \\ ${ }^{\ddagger}$ Univ. Bordeaux, LOMA, UMR5798, 33400 Talence, France \\ ${ }^{\S}$ Bionanoplasmonics Laboratory, CIC biomaGUNE, Paseo de Miramón 182, 20009 Donostia - San Sebastian, Spain \\ "Departamento de Quimica Fisica, Universidade de Vigo, 36310 Vigo, Spain \\ ${ }^{\perp}$ Ikerbasque, Basque Foundation for Science, Bilbao, Spain
}

\begin{abstract}
Investigations of the ultrafast acoustic response of metal nanosystems yield important information on the validity of continuous elastic mechanics at the nanoscale and also provide an optical way to probe nanoobject morphologies. In this context, we used femtosecond time resolved pump-probe spectroscopy to study two classes of bimetallic nanoparticles: chemically synthesized AuAg nanospheres in water in the $20-45 \mathrm{~nm}$ size range, both with alloyed and segregated core-shell morphologies, and mass selected glass embedded $\mathrm{PtAu}$ core-shell nanospheres in the very small size range $(2.3-2.5 \mathrm{~nm})$, synthesized by physical methods. The analysis of the corresponding breathing mode periods demonstrates validity of the predictions of the continuous elastic model for bimetallic nanoobjects with the investigated sizes, morphologies and composition. Moreover, discrimination of nanoparticles internal structure (alloy or core-shell) by measurement of their acoustic response is also demonstrated.
\end{abstract}

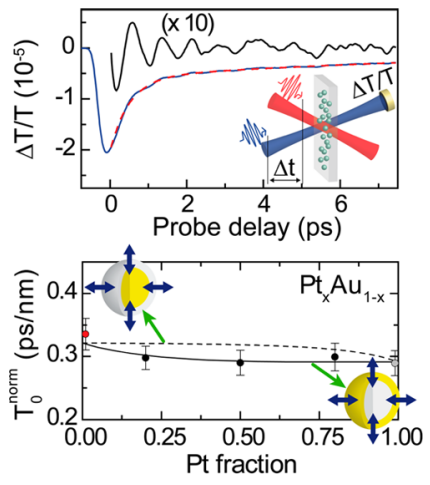

\section{INTRODUCTION}

The vibrational properties of nanometric size objects have raised a large technological and fundamental interest during the past decade. They have been motivated by creation of high frequency electrically or optically driven oscillators scaling down the object size, ${ }^{1,2}$ fundamental analysis of acoustic energy transfer at the nanoscale, ${ }^{3-11}$ and investigation of the vibrational response of objects containing a few tens of atoms, as compared to that of the bulk material. ${ }^{3,10,12-17}$ In the case of metal nanoparticles, studies performed in either the spectral or the temporal domains were mostly focused on nanoobjects formed by a single material, with various shapes and sizes down to about one nanometer. ${ }^{8,10}$ The experimentally observed vibrational mode frequencies were found to be in excellent agreement with a macroscopic elastic model, i.e., describing nanoobject vibrations with continuum mechanics model and using the elastic constants of the bulk material forming the object, and also in agreement with atomistic calculation for the smallest sizes. 15,16

Nanoobjects formed by two or more materials have been much less investigated, though information can be obtained on the effects of size reduction on the acoustic properties and on the spatial distribution and mechanical interaction of the forming materials, the latter information being difficult to obtain by other means. In this context, results obtained in heterogeneous metal based nanospheres, i.e., metal-insula tor $^{18,19}$ or insulator-metal ${ }^{20,21}$ core-shell nanoparticles, or few tens of atom clusters with surface bound molecules, ${ }^{22}$ show the large impact of the nonmetallic component on the measured time domain vibrational responses, and yield information about the material coupling in the particles.

In the case of bimetallic particles, few alloyed and segregated systems have been investigated. ${ }^{23-27}$ In the former case, acoustic vibrations of $\mathrm{AuAg}$ alloys particles were studied by Raman spectroscopy in $2 \mathrm{~nm}$ clusters $^{28}$ and $25 \mathrm{~nm}$ nano spheres, ${ }^{29}$ and by time resolved spectroscopy for larger sizes, from 40 to $90 \mathrm{~nm}$ nanoboxes and nanocages. ${ }^{30}$ As in the case of monometallic particles, results were interpreted using the continuum mechanics model combined with linearly averaged $\mathrm{Au}$ and $\mathrm{Ag}$ densities and sound velocities ${ }^{28,29}$ or fundamental elastic constants (e.g., $C_{11}, C_{12}$ and $\left.C_{44}\right)^{30}$ and found to be in agreement with atomistic modeling for AuAg alloyed 0.5-4 nm nanospheres. ${ }^{31,32}$

For a particle formed by segregated materials, their spatial distribution and mechanical interaction is expected to translate into its vibrational response. In the case of bimetallic systems, vibration of the full particle has been detected using time resolved pump-probe experiments in chemically synthesized $\mathrm{AuPb}$ spheres, AuPd rods, and AuAg bipyramids, as both parts of the particle are excited. ${ }^{23,24,27,33}$ The results show excellent 
mechanical coupling of the metallic component and thus constitute a signature of the metal distribution. ${ }^{27}$ In contrast, a Raman study of matrix embedded $\mathrm{NiAg}$ core-shell nano spheres fabricated by deposition of laser sputtered clusters (low energy cluster beam deposition, LECBD $)^{34}$ indicates vibration of only the Ag shell. ${ }^{25}$ This was ascribed to weak coupling between the components and to a larger Raman response of the $\mathrm{Ag}$ part due to surface plasmon resonance enhanced coupling. These results suggest significant influence of both the particle fabrication method, leading to different contact between material components, and the optical investigation method, involving different light metal component interactions.

To further analyze the acoustic properties of multimetallic nanosystems, we have investigated the vibrational response of alloyed or segregated bimetallic nanospheres synthesized by either chemical or physical means using a time resolved pumpprobe technique. The effect of segregation and alloying was investigated in colloidal solutions of alloyed and core-shell $\mathrm{AuAg}$ nanospheres with sizes in the 20-45 $\mathrm{nm}$ range and different compositions, and the results were interpreted in terms of the elastic model, which is fully applicable in this size range. The effect of structure and possible modification of the acoustic response of a thin layer was investigated for small size $(2-3 \mathrm{~nm})$ core-shell PtAu nanospheres fabricated by LECBD. In this size range, depending on the composition, the shell layer may be either incomplete or formed by a monatomic layer, offering the unique possibility of experimentally investigating the acoustic properties of such small systems.

\section{SAMPLES}

Measurements were performed in different alloyed or segregated bimetallic nanospheres whose compositions, morphologies, diameters, size dispersions and embedding environment are summarized in Table 1. AuAg nanospheres

\section{Table 1. Characteristics of Different Samples ${ }^{a}$}

$\begin{array}{ccccc}\text { name } & \text { composition } & \text { matrix } & \text { morphology } & D_{0}(\mathrm{~nm}) \\ \text { s1 } & \mathrm{Au}_{0.25} \mathrm{Ag}_{0.75} & \text { water } & \text { alloy } & 45 \pm 3 \\ \text { s2 } & \mathrm{Au}_{0.50} \mathrm{Ag}_{0.50} & \text { water } & \text { alloy } & 36 \pm 10 \\ \text { s3 } & \mathrm{Au}_{0.75} \mathrm{Ag}_{0.25} & \text { water } & \text { alloy } & 33 \pm 3 \\ \text { s4 } & \mathrm{Au}_{0.36} \mathrm{Ag}_{0.64} & \text { water } & \text { core shell } & 21 \pm 6 \\ \text { s5 } & \mathrm{Au}_{0.10} \mathrm{Ag}_{0.90} & \text { water } & \text { core shell } & 33 \pm 10 \\ \text { s6 } & \mathrm{Pt}_{0.20} \mathrm{Au}_{0.80} & \text { silica } & \text { core shell } & 2.5 \pm 0.1 \\ \text { s7 } & \mathrm{Pt}_{0.50} \mathrm{Au}_{0.50} & \text { silica } & \text { core shell } & 2.5 \pm 0.1 \\ \text { s8 } & \mathrm{Pt}_{0.80} \mathrm{Au}_{0.20} & \text { silica } & \text { core shell } & 2.3 \pm 0.1\end{array}$

${ }^{a}$ Nanoparticle composition (atomic fraction), surrounding matrix, predicted internal morphology, and external average diameter $\left(D_{0}\right)$. Uncertainties correspond to standard deviations of size distribution. For core-shell nanoparticles, the element expected in the core is $\mathrm{Au}$ (samples s4 and s5), Pt (samples s6-s8).

in water were synthesized both in an alloy configuration (samples s1-s3) and in a core-shell geometry (s4 and s5). In the case of $\mathrm{AuAg}$ nanoalloys $\left(\mathrm{Au}_{0.25} \mathrm{Ag}_{0.75}, \mathrm{Au}_{0.50} \mathrm{Ag}_{0.50}\right.$ and $\mathrm{Au}_{0.75} \mathrm{Ag}_{0.25}$, samples $\mathrm{s} 1-\mathrm{s} 3$ respectively), synthesis was obtained by the methods described by Link et al. ${ }^{35}$ and Rodríguez González et al. ${ }^{36}$ Briefly, a constant total metal molar concentration of $0.5 \mathrm{mM}$ was used, and the $\mathrm{Au}: \mathrm{Ag}$ molar ratio was adjusted through the addition of the corresponding concentrations of $\mathrm{HAuCl}_{4}$ and $\mathrm{AgNO}_{3}$. In a typical synthesis, to a boiling aqueous solution of metal salts $(100 \mathrm{~mL})$, preheated sodium citrate $1 \mathrm{wt} \%$ was added $(5 \mathrm{~mL})$ under vigorous stirring, and the boiling was continued for $30 \mathrm{~min}$. Finally, the solution was allowed to cool down to room temperature. Absorption spectra of AuAg alloy nanospheres (Figure $1 \mathrm{~b}$ ), with the three different compositions are shown in (a)

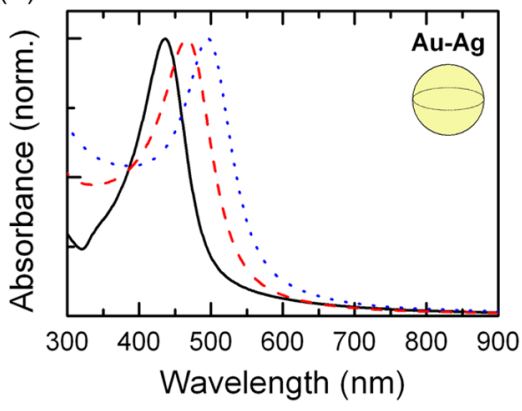

(c)

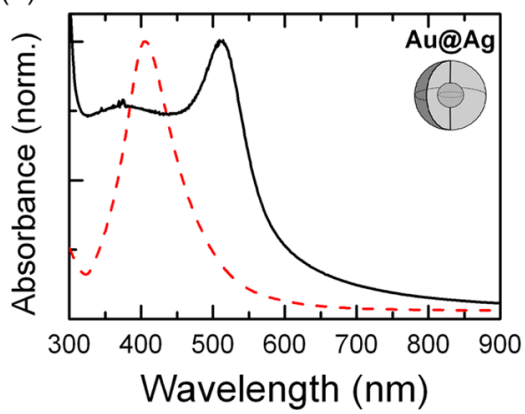

(b)

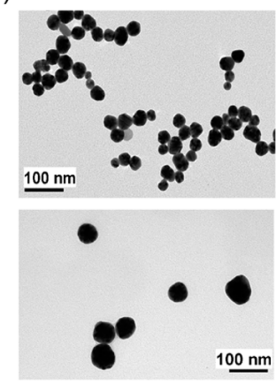

(d)

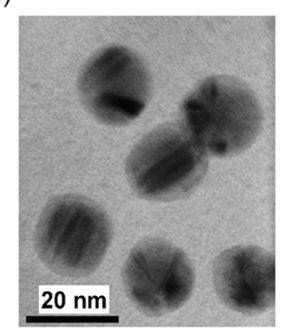

Figure 1. (a) Normalized absorption spectra of water dispersed AuAg nanoalloys (full, dashed and dotted line for samples s1, s2, and s3, respectively) and (b) transmission electron microscope (TEM) images of solution $\mathrm{Au}_{0.75} \mathrm{Ag}_{0.25}$ (sample s3, top) and $\mathrm{Au}_{0.50} \mathrm{Ag}_{0.50}$ (sample $\mathrm{b}$, bottom). (c) Absorption spectra of AuAg core-shell samples (full and dashed line for sample s4 and s5, respectively) and (d) TEM image of sample $\mathrm{Au}_{0.36} \mathrm{Ag}_{0.64}$ (sample s4).

Figure 1a. They correspond to diameters of $45 \pm 3 \mathrm{~nm}, 36 \pm$ $10 \mathrm{~nm}$ and $33 \pm 3 \mathrm{~nm}$ for samples s1-s3, respectively. As expected, their surface plasmon resonance (SPR) ${ }^{37}$ shifts to longer wavelengths upon increasing gold molar ratio, ${ }^{35,38-42}$ its maximum position linearly varying with composition. AuAg core-shell samples (samples s4 and s5) with gold core diameter of $15 \mathrm{~nm}$ and two different silver shell thicknesses ( 3 and $9 \mathrm{~nm}$, resulting in $\mathrm{Au}_{0.36} \mathrm{Ag}_{0.64}$ and $\mathrm{Au}_{0.10} \mathrm{Ag}_{0.90}$ nanoparticles with diameters of $21 \pm 6 \mathrm{~nm}$ and $33 \pm 10 \mathrm{~nm}$ respectively, see Figure 1c) were also obtained by chemical synthesis. In this case spherical gold nanoparticles with $15 \mathrm{~nm}$ diameter (the cores) were first prepared by adding $12.5 \mathrm{~mL}$ of $3.4 \times 10^{-2} \mathrm{M}$ sodium citrate to $250 \mathrm{~mL}$ of a boiling solution of $5 \times 10^{-4} \mathrm{M} \mathrm{HAuCl}_{4}$, boiling being further continued for 15 min. ${ }^{43}$ For $3 \mathrm{~nm} \mathrm{Ag}$ layer deposition, $5 \mathrm{~mL}$ of $0.1 \mathrm{M}$ ascorbic acid, $0.25 \mathrm{~mL}$ of $10 \mathrm{mM} \mathrm{AgNO}_{3}$ and finally $2.5 \mathrm{~mL}$ of the $\mathrm{Au}$ colloid were sequentially added to $100 \mathrm{~mL}$ of $50 \mathrm{mM} \mathrm{CTAB}$ solution. Finally $0.5 \mathrm{~mL}$ of $1.0 \mathrm{M} \mathrm{NaOH}$ was added dropwise while stirring. To grow $9 \mathrm{~nm}$ silver shells, $1.25 \mathrm{~mL}$ of $10 \mathrm{mM}$ $\mathrm{AgNO}_{3}$ and $2.5 \mathrm{~mL}$ of $1.0 \mathrm{M} \mathrm{NaOH}$ were used instead. Silver coating was accompanied by a rapid color change from red to a different yellowish tone, depending on the Ag shell thickness obtained. The values of shell thickness and particles diameter were measured by high resolution transmission electron microscopy. Sample s4 (Figure 1d), which contains a smaller amount of silver, shows a spectrally similar SPR to that of gold 
nanoparticles, ${ }^{43,44}$ while the absorption spectrum of sample s5, having a thicker silver shell and a very small amount of gold in the core, is similar to the spectrum of a silver monometallic sphere, characterized by a SPR around $400 \mathrm{~nm}$ (Figure 1c). ${ }^{45}$

Three samples of quasi spherical nanoparticles $\left(\mathrm{Pt}_{0.20} \mathrm{Au}_{0.80}\right.$, $\mathrm{Pt}_{0.50} \mathrm{Au}_{0.50}$, and $\mathrm{Pt}_{0.80} \mathrm{Au}_{0.20}$, from s6 to $\mathrm{s} 8$ respectively) with small sizes (external diameter ranging from $2.3 \pm 0.1$ to $2.5 \pm$ $0.1 \mathrm{~nm}$ ) embedded in a silica matrix were obtained by the LECBD technique. ${ }^{13,34,46,47}$ In this setup, laser induced ablation of a bulk target with the chosen stoichiometric composition generates a bimetallic plasma. Its subsequent cooling by collisions with a helium gas induces the nucleation and growth of small clusters with the same average composition as the target. Charged clusters are expanded in the form of a molecular beam and are size selected by an electrostatic quadrupolar deviator. They are thereafter deposited on the surface of a glass slide, simultaneously with a silica matrix evaporated by electron bombardment. The deposition of an additional silica layer provides a supplementary protection from oxidation. Electrostatic mass selection guarantees a very narrow size selection, resulting in a $\pm 4 \%$ (see Table 1) size distribution width. ${ }^{47}$ Deposited nanoparticles have a quasi spherical shape and their surfaces are free from contaminant molecules. This aspect is particularly important for small nanoparticles as, for the size considered here (around $2.5 \mathrm{~nm}$ ), more than $50 \%$ of the atoms lie close to the surfaces ${ }^{13}$ and investigated properties can thus be sensitively affected by molecules attached to the external shell. Clusters initially nucleate with an atomic ratio given by the target composition. However, between clusters formation and their stabilization on the substrate, their chemical configuration may evolve (atomic interdiffusion). Depending on kinetic and thermodynamic constraints, nanoparticles with different structures can be formed, e.g., more or less ordered alloys, segregated systems as concentric core-shell, or side separated (Janus geometry). ${ }^{48}$ In the case of PtAu mixtures, the high miscibility gap in the respective alloy bulk phases and the larger surface tension of $\mathrm{Pt}$ as compared to $\mathrm{Au}$ are in favor of the formation of $\mathrm{Pt} @ \mathrm{Au}$ (i.e., PtAu with Pt in the core) core-shell structures. ${ }^{49}$ However, its structure proves to be dependent on preparation conditions, composition and environment. For instance, colloidal chemistry has shown the possibility of producing both Pt@Au and Au@Pt core-shell particles $(D>10 \mathrm{~nm}) .{ }^{50}$ Nonetheless, a Pt@Au core-shell formation is predicted to be favored in the small size range, ${ }^{51}$ even if the growth of side separated clusters (Janus) cannot be totally ruled out when surface effects are dominating as it is the case for smallest clusters $(D<5 \mathrm{~nm})$.

For samples $s 6-s 8$, the nanoparticles concentration is too low to detect their absorption spectra. These are however still expected to show a SPR peak, in spite of the small size of nanoparticles (from 2.3 to $2.5 \mathrm{~nm}$ ), as observed in denser systems and predicted both on monometallic nanoparticles of similar dimensions ${ }^{52}$ and on bimetallic segregated PtAu systems. $^{39,53}$

\section{EXPERIMENTS AND RESULTS}

The elastic behavior of different nanosystems was measured using a time resolved two color femtosecond pump-probe setup, $8,10,54$ the acoustic response being determined by measuring the modulation of the optical sample transmission induced by mechanical vibrations. A first laser pulse (pump) excites the electrons of the metallic nanoparticles, the relative change of optical transmission of a second delayed probe pulse yielding information on transient processes in the nanoparticles such as electron and lattice thermalization, ${ }^{55-57}$ mechanical breathing ${ }^{3,8,9,13,58,59}$ and thermal transfer to the environment. ${ }^{60}$ For generating the pump and probe synchronized pulses at the most appropriate wavelengths for acoustic vibration detection, two laser systems were alternatively employed, both based on a Ti:Sa cavity oscillator. In the first configuration, the Ti:Sa oscillator delivers infrared pulses with a duration of approximately $50 \mathrm{fs}, 76 \mathrm{MHz}$ repetition rate and pulse energy of $10 \mathrm{~nJ}$. After beam splitting by a semitransparent plate, one of the two infrared beams is frequency doubled in a $200 \mu \mathrm{m}$ thick BBO crystal. The infrared $(\lambda \approx 800 \mathrm{~nm})$ and blue $(\lambda \approx 400$ $\mathrm{nm})$ pulses were used as pump and probe beams, respectively. The pump-probe time delay is swept on a range of a few tens of ps with a mechanical delay stage. Mechanically chopping the pump beam at $100 \mathrm{kHz}$ and demodulating the photodiode signal by a lock in amplifier allows to achieve a relative transmission change $\Delta T / T$ signal with sensitivity down to $10^{-7}$. The second configuration is based on a $\mathrm{Ti}: \mathrm{Sa}$ regenerative amplified system. In this case ${ }^{27,61}$ the infrared pulse duration is approximately $120 \mathrm{fs}$, with a $250 \mathrm{kHz}$ repetition rate and pulse energy of a few $\mu \mathrm{J}$. By combining the amplified system with an optical parameter amplifier (OPA), pulses in the full visible range from 500 to $700 \mathrm{~nm}$ can be generated. In this configuration, part of the amplified beam before the OPA is used as pump, after frequency doubling. This second configuration thus allows a better tunability in the visible range and time resolved signals with a bigger contrast, due to stronger excitation, at the price of a higher noise $(\Delta T / T$ noise level around $10^{-5}$ ).

A representative pump-probe signal for $\mathrm{Au}_{0.50} \mathrm{Ag}_{0.50}$ (sample s2) obtained with the regenerative amplified system (pump wavelength $\lambda_{\text {pump }}=400 \mathrm{~nm}$ and probe wavelength $\lambda_{\text {probe }}=500$ $\mathrm{nm})$ is shown in Figure 2a (blue line). Probe transmission change $\Delta T / T$ being essentially proportional to the excess energy in the metal electron gas, ${ }^{54,55,62}$ its fast rise and fall reflects heating of the electrons by the pump pulse and their subsequent cooling by electron to lattice energy transfer. The latter results in a thermal dilation of the nanoparticle lattice equilibrium diameter, ${ }^{3,8}$ which launches acoustic vibrations, the fundamental breathing mode being preferentially excited and detected for metallic nanoparticles. ${ }^{9,19}$ The resulting modu lation of the nanoparticle volume affects the optical response through a periodic variation of the dielectric constant, which is at the origin of the oscillation in the $\Delta T / T$ signal (Figure 2a). Frequency of oscillations in the time resolved signal thus directly shows the breathing mode vibrational period, while their damping reflects vibrating mode energy loss (homoge neous damping) and size and shape dispersion effects (inhomogeneous damping). On longer pump-probe delays (on a few tens of ps time scale) a slow varying background signal reflects global heating and cooling of the nanoparticles by heat transfer to the environment. ${ }^{60}$ To measure oscillation period and damping rate, the oscillating contribution (black solid line in Figure 2a) is first singled out by subtracting from the decaying part of the raw signal (blue solid line) its fit by a two exponential function (red dashed line), which reflects electron cooling and heat transfer to the environment. Both period and decaying time can then be precisely obtained by fitting the oscillating part (black solid line) with a damped oscillating function. Fourier transforming the oscillating contribution (Figure 2a insert) alternatively leads to the same frequency. 

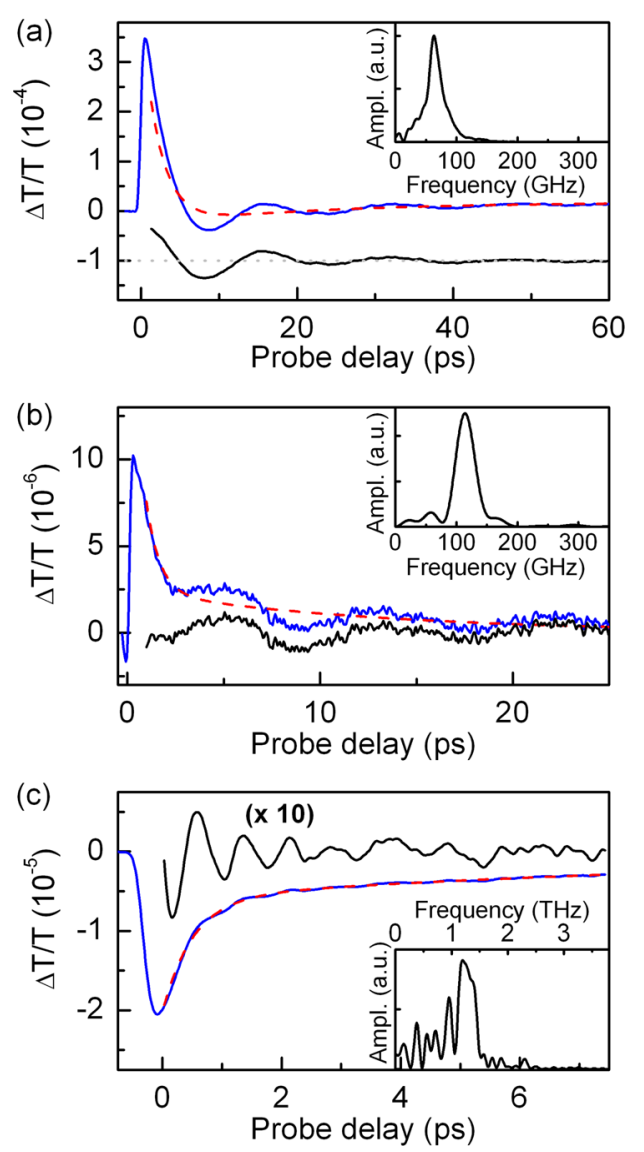

Figure 2. (a) Time resolved transient absorption signal of sample $\mathrm{Au}_{0.50} \mathrm{Ag}_{0.50}$ (sample s2), measured at $\lambda_{\text {pump }}=400 \mathrm{~nm}, \lambda_{\text {probe }}=500 \mathrm{~nm}$ and pump fluence $\mathrm{F}_{\text {pump }}=200 \mu \mathrm{J} / \mathrm{cm}^{2}$. Blue solid line: raw signal. Dashed red line: two exponential fit of the signal decay. Black solid line: oscillating contribution after subtraction of the exponential decay (downshifted for clarity). Insert: Fourier transform of the oscillating contribution. (b) Same as part a for sample $\mathrm{Au}_{0.10} \mathrm{Ag}_{0.90}$ (sample s5, $\lambda_{\text {pump }}=860 \mathrm{~nm}, \lambda_{\text {probe }}=430 \mathrm{~nm}$ and $\mathrm{F}_{\text {pump }}=50 \mu \mathrm{J} / \mathrm{cm}^{2}$ ) and $(\mathrm{c})$ $\mathrm{Pt}_{0.20} \mathrm{Au}_{0.80}$ (sample s6, $\lambda_{\text {pump }}=810 \mathrm{~nm}, \lambda_{\text {probe }}=405 \mathrm{~nm}$ and $\mathrm{F}_{\text {pump }}=$ $300 \mu \mathrm{J} / \mathrm{cm}^{2}$ ).

Time resolved pump-probe characterizations were repeated for all the samples, measured signals having different amplitudes depending on the excitation pulse energy (Ti:Sa oscillator or amplified laser system), concentration of nano particles in the sample, and wavelength dependent absorption. Choice of the probe wavelength close to the corresponding SPR (for samples s1-s5) allows the largest modulation amplitude. ${ }^{3}$ Transient signals obtained on samples $\mathrm{Au}_{0.10} \mathrm{Ag}_{0.90}$ (sample s5, oscillator with $\lambda_{\text {pump }}=860 \mathrm{~nm}$ and $\lambda_{\text {probe }}=430 \mathrm{~nm}$ ) and $\mathrm{Pt}_{0.20} \mathrm{Au}_{0.80}$ (sample s6, oscillator with $\lambda_{\text {pump }}=810 \mathrm{~nm}$ and $\lambda_{\text {probe }}=405 \mathrm{~nm}$ ), as well as extraction of their oscillating parts are shown in Figures $2 b$ and $2 c$, respectively.

Breathing mode periods being proportional to particle diameters, ${ }^{63,64}$ analysis of the elastic properties of bimetallic systems is carried out by comparing the variation of the normalized period over diameter ratio $T_{0}^{\text {norm }}=T_{0} / D_{0}$ as a function of composition. In the case of mass selected silica embedded samples (samples s6 to s8), having a very small size dispersion $( \pm 4 \%)$, the measured period can be normalized directly by the average diameter $D_{0}$. A more accurate analysis is required in the case of broader size distributions, as in the case of colloidal AuAg samples (samples s1-s3), which induce both important inhomogeneous damping (due to dephasing of the different oscillating contributions for each size) and frequency shift, both these effects being a consequence of the linear dependence of the period on the nanoparticle diame ter. $3,8,13,15,64$ The former adds to homogeneous damping due to relaxation of the breathing mode through energy transfer to the surrounding matrix ${ }^{4,6,65-68}$ and, possibly, to other vibra tional modes via anharmonic interactions ${ }^{69}$ or interactions with crystalline defects. ${ }^{5,66}$

Size distribution is accounted for by the following model. As, for a metal nanosphere of diameter $D$ in the size range considered here, the amplitude of the ultrafast transient response is proportional to its volume $V(D)=\pi D^{3} / 6$ (through its linear absorption cross section), ${ }^{70}$ its contribution to the oscillating part of the transient absorption signal is given by $3,6,58,66$

$$
s(D, t)=s_{0} V(D) \exp \left(-\frac{t}{\tau_{h}(D)}\right) \cos \left(\frac{2 \pi t}{T(D)}-\phi_{0}\right)
$$

where $T(D)=T_{0}^{n o r m} D$ and $\tau_{h}(D)=\tau_{h, 0}^{\text {norm }} D$ are the breathing mode period and homogeneous damping time, respectively, $\tau_{h, 0}^{\text {norm }}=\tau_{h, 0} / D_{0}$ corresponding to nanoparticles with mean diameter $D_{0}, s_{0}$ is an amplitude factor and $\varphi_{0}$ is the oscillation phase, considered at a first approximation as a fit parameter independent of $D^{3,4,8,58}$ By considering a Gaussian size distribution $P(D)$ with standard deviation $\Delta D$ :

$$
P(D)=P_{0} \exp \left[-\frac{1}{2} \frac{\left(D-D_{0}\right)^{2}}{\Delta D^{2}}\right]
$$

with $\int P(D) \mathrm{d} D=1$, the oscillating part of the transient absorption signal resulting from the sum of all contributions is given by

$$
\frac{\Delta T}{T}(t)=\int_{D=0}^{\infty} P(D) s(D, t) \mathrm{d} D
$$

For a given size distribution (fixed $D_{0}$ and standard deviations, see Table 1 and Figure 3a for samples s1 and s2), eq 3 thus reproduces the experimental transient signal with amplitude $s_{0}$, normalized period $T_{0}^{\text {norm }}$, normalized damping time $\tau_{h, 0}^{n o r m}$, and phase $\varphi_{0}$ as free parameters, determination of $T_{0}^{\text {norm }}$ being the main goal of this analysis. $T_{0}^{\text {norm }}$ values obtained by fitting the $\Delta T / T$ signal with eq 3 (Figure $3 \mathrm{~b}$, red lines) are plotted in Figure $3 c$ (full circles, samples s1-s3) as a function of nanoparticle composition. Black crosses in Figure $3 \mathrm{c}$ represent the normalized breathing periods obtained by a direct fit of the oscillating part of the transient signal with a single sinusoidal function (or by its Fourier transform), dividing the period by the corresponding mean diameter $D_{0}$ (see Figure 2 ), without taking size dispersion into account. As expected, direct fitting leads to a negligible discrepancy in the case of a small size dispersion (as for $\mathrm{Au}_{0.25} \mathrm{Ag}_{0.75}$, sample s1), the error being more important for broader distributions $\left(\mathrm{Au}_{0.50} \mathrm{Ag}_{0.50}\right.$, sample s2). In the latter case, not taking size dispersion into account yields a considerably larger value for the normalized period (Figure 3c), since the dominant contribution to the signal comes from vibrations of larger particles (absorption being proportional to nanoparticle volume), an effect that systematically shifts the resulting breathing oscillations to longer periods.

For broad size distributions $\left(\mathrm{Au}_{0.50} \mathrm{Ag}_{0.50}\right.$, sample s2, Figure 3, right column), the dominant contribution to experimental 

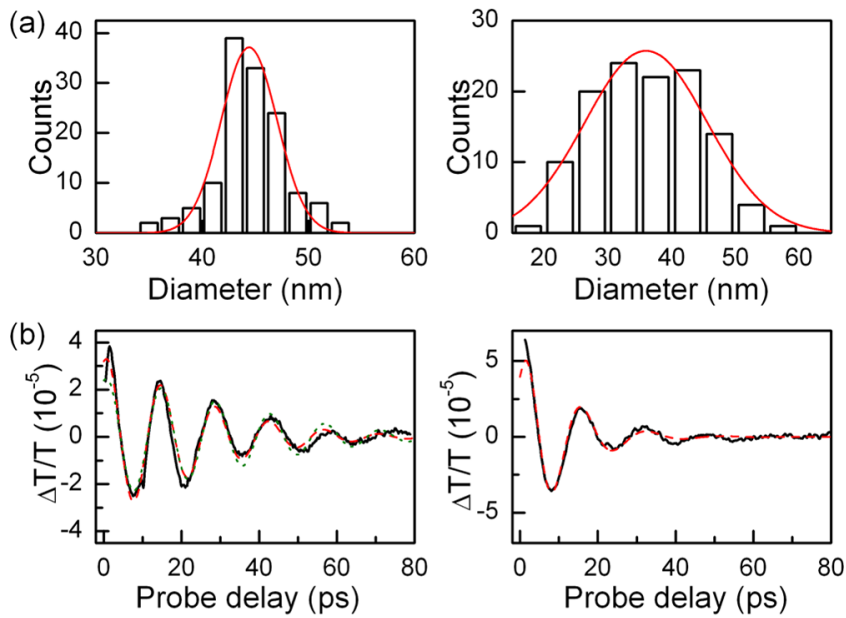

(c)

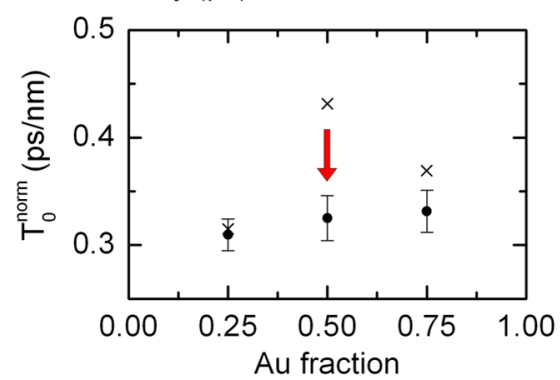

Figure 3. (a) Size distribution of samples $\mathrm{Au}_{0.25} \mathrm{Ag}_{0.75}$ (left, sample s1) and $\mathrm{Au}_{0.50} \mathrm{Ag}_{0.50}$ (right, sample s2). Red lines are fits of the distributions, yielding mean values and standard deviations of Table 1. (b) Oscillating parts of the time resolved signals (black lines) for the two samples. Red dashed lines are fits using eq 3 with $s_{0}, T_{0}^{\text {norm }}, \tau_{h, 0}^{\text {norm }}$ and $\varphi_{0}$ as free parameters. The green dotted line represents a fit with $\tau_{h, 0}^{\text {norm }}$ set to the value expected for $\mathrm{Ag}$ nanoparticles in water. (c) Normalized breathing mode periods deduced by a fit with a single sinusoidal function (crosses) and by the complete fit taking into account size distribution (full circles, see text).

damping time comes from inhomogeneous effects. This prevents extracting a $\tau_{h, 0}^{\text {norm }}$ value through the analysis above, a fit with no homogeneous contribution $\left(\tau_{h, 0}^{\text {norm }} \rightarrow \infty\right)$ already correctly reproducing the $\Delta T / T$ signal (Figure $3 \mathrm{~b}$, right column, red dashed line). In the case of a narrow size distribution (Figures 3a and 3b, sample s1, left column), both inhomogeneous and homogeneous contributions play a role in the observed acoustic damping, even if the former still dominates. The $\tau_{h, 0}^{\text {norm }}$ value deduced by the fit of sample $\mathrm{Au}_{0.25} \mathrm{Ag}_{0.75}$ (sample s1) through eq 3 (Figure 3b, left column, red dashed line) is equal to $(1.0 \pm 0.5) \mathrm{ps} / \mathrm{nm}$. It is however smaller than the one expected for particle to environment energy transfer in the case of water immersed pure $\mathrm{Ag}$ or $\mathrm{Au}$ spheres (corresponding to 2.8 and $5.7 \mathrm{ps} / \mathrm{nm}$ respectively, ${ }^{3,64}$ with negligible contribution from solvent viscosity ${ }^{7,68}$ ), the fit of the transient absorption signal with $\tau_{h, 0}^{\text {norm }}$ set to the theoretical Ag value showing a slightly longer oscillation damping time (Figure $3 \mathrm{~b}$, left column, green dotted line). The difference between the values expected for monometallic systems and the one deduced experimentally for the bimetallic spheres could possibly be ascribed to AuAg alloying, leading to shorter homogeneous $\tau_{h, 0}^{\text {norm }}$, due to additional mechanism of relaxation of the breathing mode energy (e.g., anharmonic coupling to other vibrational modes, or interaction with internal defects). Further contribution to damping could also arise from uncertainties in the size and shape dispersions of nanoparticles, possibly deviating from a perfect sphere. However, a deviation of breathing mode periods smaller than $5 \%$ is expected for elongations up to $50 \%, 8,13,71$ which is the upper limit of elongations deduced from TEM images (Figure 1). Nonethe less, it should be noted that deduced $T_{0}^{\text {norm }}$ values are negligibly affected by the values of homogeneous damping time $\tau_{h, 0}^{\text {norm }}$ considered here.

As its variations with size are expected to be small, $3,4,58$ oscillating phase $\varphi_{0}$ has been considered constant throughout the analysis. The values deduced for samples $s 1$ and $\mathrm{s} 2\left(\varphi_{0}=\right.$ $0.6 \pm 0.1 \mathrm{rad}$ and $0.4 \pm 0.1 \mathrm{rad}$ respectively) are consistent with the sample sizes, assuming indirect excitation of the breathing mode by lattice heating ${ }^{4,8}$ and repeating the analysis above after replacing $\varphi_{0}$ with its complete size dependent expression also provides the same results.

\section{DISCUSSION}

Normalized periods for water immersed $\mathrm{AuAg}$ alloyed nano particles (samples $s 1-\mathrm{s} 3$ ) deduced by the analysis above are reported in Figure 4a (solid dots) as a function of gold
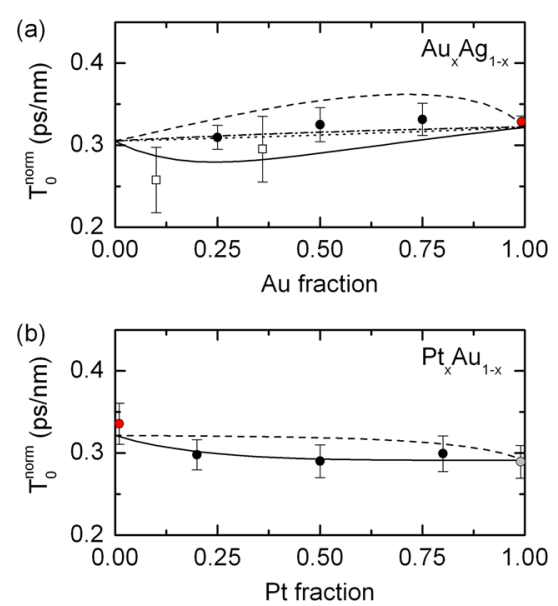

Figure 4. Normalized breathing mode periods $T_{0}^{\text {norm }}=T_{0} / D_{0}$ as a function of sample composition for AuAg (a, samples s1 s3 and s4 s5 in black dots and empty squares, respectively) and PtAu (b, samples s6 s8 in black dots). Solid lines correspond to expected values calculated by continuous elasticity theory and bulk elastic constants by Ledbetter $^{74}$ (except for $\left.\mathrm{Pt}\right)^{75}$ for a core-shell configuration Au@Ag (Au core) and Pt@Au (Pt core). Dashed lines correspond to Ag@Au (Ag core) and Au@Pt (Au core) in parts a and b respectively. Colored points are experimental reference values for monometallic nano spheres. Dotted and dash dotted lines in part a show predicted periods for $\mathrm{AuAg}$ alloyed nanospheres obtained by a weighted average of either sound velocities or fundamental elastic constants $C_{11}, C_{12}$, and $C_{44}$ respectively.

composition. Periods of AuAg core-shell nanoparticles are also reported (samples s4 and s5, empty squares). Because of a complex dispersion in the core shape and diameter, as well as in the shell thickness, extraction of the average particle breathing mode period with the previous analysis was not possible for these two samples. Larger error bars account for these effects. Values for PtAu core-shell small nanospheres (samples s6-s8) are reported in Figure $4 \mathrm{~b}$. Because of the very small size dispersions, analysis of inhomogeneous broadening was not necessary for these mass selected samples, as in this case the apparent breathing mode period (Figure 2) can be directly normalized with the average diameter. When available, normalized breathing mode periods for monometallic nano 
spheres were taken from experiments in the literature on nanoparticles within the same matrix (water or transparent solid matrix) and are shown as reference. This is the case for water immersed $\mathrm{Au}$ (Figure $4 \mathrm{a}$, red circle), ${ }^{58}$ silica embedded $\mathrm{Au}$ (Figure $4 \mathrm{~b}$, red circle) $)^{15}$ and $\mathrm{Pt}$ (Figure $4 \mathrm{~b}$, gray circle) ${ }^{13}$ nanospheres. Note that by changing the gold particle environment from water to silica, a decrease in period of the order of $4 \%$ is to be expected. ${ }^{3,4,13}$

The oscillating periods expected for a core-shell config uration are compared and reported in Figure 4 for comparison. Periods were calculated by resolving Navier equations of a core-shell system in a homogeneous surrounding matrix after imposing, as boundary conditions, continuity of the displace ment and of the radial component of the stress tensor at the intermediate interface and at the nanoparticle-matrix inter face. ${ }^{9,19,72}$ Solid (dashed) lines in Figures $4 \mathrm{a}$ and $4 \mathrm{~b}$ correspond to core-shell Au@Ag (Ag@Au) and Pt@Au ( $\mathrm{Au} @ \mathrm{Pt})$, respectively. The theoretical values of breathing mode periods of monometallic nanospheres (values in Figure 4, parts a and b, corresponding to 0 and 1 in the horizontal axis) match those calculated by continuous mechanics elasticity equations ${ }^{64,73}$ using the same bulk polycrystalline elastic constants. Note that in the case of monometallic $\mathrm{Au}$ and $\mathrm{Pt}$ nanospheres, a difference in the estimation of the breathing mode periods as large as $10 \%$ is obtained depending on the set of elastic constants used, ${ }^{15,74,75}$ while this is not the case for Ag. For all the computations in Figure 4, the set of elastic constants best matching experimental reference values for each monometallic constituent has thus been retained, this being the elastic constants by Ledbetter ${ }^{74}$ for $\mathrm{Au}$ and Ag, and Kaye and Laby ${ }^{75}$ for Pt (Figure 4b). Values of density, longitudinal and transverse sound velocity for water (Figure 4a) are $\rho=1000$ $\mathrm{kg} / \mathrm{m}^{3}, v_{l}=1482 \mathrm{~m} / \mathrm{s}$ and $v_{t}=0 \mathrm{~m} / \mathrm{s}$. In the case of silica embedded nanoparticles (samples s6 to s8, Figure $4 \mathrm{~b}$ ), calculations were made for free spheres, as silica matrix is highly porous with pore sizes larger than particle diameters (porosity $>30 \%),{ }^{76}$ resulting in a weak effective metal matrix contact. This assumption however only weakly affects vibra tional period computations, ${ }^{15}$ the main effect being expected on damping (as also observed in pressure dependent vibrational studies on glass embedded silver nanospheres which confirmed the imperfect mechanical contact between the metal and surrounding solid matrix). ${ }^{77,78}$

For AuAg alloyed nanospheres (Figure 4a), the effect of alloying on the breathing mode periods was computed by applying the same macroscopic acoustic approach based on continuous mechanics elasticity equations as for monometallic nanospheres, ${ }^{64}$ and using as input material elastic parameters a weighted average of the elastic constants of the two metals. The averaged quantities are either (1) the densities and sound velocities of the two metals (Figure 4a, dotted line) or (2) their densities and $C_{11}, C_{12}$, and $C_{44}$ fundamental elastic constants, the Young modulus and Poisson ratio of the polycrystalline samples being then calculated, in the latter case, starting from these weighted parameters (dash dotted lines). ${ }^{30,79,80}$ Although there is no ultimate conclusion in the literature on the dependence of elastic properties of bimetallic bulk alloys on composition, different investigations reporting linear averaging of the fundamental elastic constants upon alloying ${ }^{80-82}$ or a slight deviation from linearity, ${ }^{83,84}$ we generally expect breathing mode periods to lie in the range between those for the individual components. This has been confirmed, in the 1$4 \mathrm{~nm}$ range, by molecular dynamics calculations on $\mathrm{AuAg}$ nanoalloys. $^{31,32}$ It should be underlined that crystallinity has not been taken into account in the computations of Figure 4, as for spherical nanoparticles the variation of the radial breathing mode frequencies with crystal orientation is negligible, ${ }^{8,71,85}$ unlike the quadrupolar mode, which is significantly affected by crystal orientation. ${ }^{86}$

Experimental breathing mode normalized periods of $\mathrm{AuAg}$ nanoalloys (solid dots in Figure 4a) show values consistent with those corresponding to the two different averages of elastic parameters (dotted and dash dotted lines). No unexpected signature of alloying on the breathing mode frequencies was observed experimentally. These values are more distant from the periods computed for core-shell configurations (solid and dashed lines). In addition, breathing mode periods of AuAg core-shell nanoparticles (empty squares in Figure 4a) are also consistent with values expected for the corresponding coreshell structure (solid line). For AuAg bimetallic nanoparticles, measurement of the breathing mode frequencies by ultrafast spectroscopy allows to discriminate between internal nano particle configuration (alloyed or core-shell, in the latter case allowing determination of the element in the core), although for gold and silver the overall difference between the resulting breathing mode periods is limited. It should be reminded that, when the two combined metals present a more significant difference in their elastic properties, and the formed nanoobject has an anisotropic shape, as was shown for Pd coated $\mathrm{Au}$ nanorods, ${ }^{27}$ variations of vibrational mode frequencies with the amount and the position of the metal deposited around the inner core could be sensitively larger, also providing a way to probe mass deposition of the external metal.

This is indeed confirmed in the case of PtAu nanospheres (Figure $4 \mathrm{~b}$ ), where experimental normalized values also lie very close to the theoretical predictions (Figure $4 \mathrm{~b}$, solid line) corresponding to the expected configuration ( $\mathrm{Pt} @ \mathrm{Au}$ coreshell with Pt core), periods for Au@Pt structure (Au core, dashed line) being more distant from the corresponding experimental values. These computations in the core-shell configuration are based on a model configuration of a homogeneous and radially symmetrical core-shell structure. However, in the small size regime, this morphology is not realistic for all the samples, as for instance the size and composition of samples s7 and s8 (2.5 nm $\mathrm{Pt}_{0.50} \mathrm{Au}_{0.50}$ and 2.3 $\mathrm{nm} \mathrm{Pt} \mathrm{t}_{0.80} \mathrm{Au}_{0.20}$ respectively) would lead to a calculated Pt@Au structure (Pt core) characterized by a gold homogeneous shell with a thickness smaller than that of a monatomic layer. Similarly, when computing the breathing mode periods for the $\mathrm{Au} @ \mathrm{Pt}$ core-shell configurations with a gold core the size and atomic fraction of samples s6 and s7 would lead to unrealistically thin Pt shells. Bimetallic nanoparticles of these sizes are more likely characterized by an asymmetric morphology with a monatomic thin shell only partially covering the core, with part of the atoms of the core in contact with the external matrix, forming a Janus like structure. A more refined model can be used in this geometry, by computing the breathing modes through finite element method (FEM). ${ }^{9,71}$ Janus like structures have been modeled as nanospheres with the same external diameter, total number of atoms and atomic fractions as the ones of samples s6 to s8 (see Supporting Information). The thickness of the monatomic shell layer, only partially covering the core, has been set to 0.318 and $0.306 \mathrm{~nm}$, corresponding to the diameter of the free electron spheres of $\mathrm{Au}$ and $\mathrm{Pt}$ respectively, ${ }^{87}$ and its extension defined by an azimuthal angle $\alpha$ (see Figure S1 and Table S1 in Supporting 
Information). The elastic constants used for the core and the incomplete shell are still those of polycrystalline bulk materials, this choice being nonetheless a crude approximation partic ularly in the case of a monatomic layer. The breathing mode periods deduced by FEM modeling (full and empty diamonds in Figure S2 for Pt@Au and Au@Pt core-shell structures respectively) match the ones computed for homogeneous radially symmetrical core-shell nanospheres, confirming at first sight the validity of the predictions regardless of the exact degree of coverage (partially extended or complete shell).

\section{CONCLUSIONS}

Time resolved ultrafast spectroscopy was used to investigate the vibrational dynamics of bimetallic alloyed and core-shell nanoparticles, in order to elucidate the impact of combining two different metals on their acoustic response. The experi ments were performed on water immersed chemically synthe sized AuAg nanospheres with alloyed composition with different AuAg ratio in the 33-45 nm range and AuAg coreshell nanoparticles of 21 and $33 \mathrm{~nm}$, and on small silica embedded 2.3-2.5 nm segregated PtAu nanospheres. Optical excitation and detection of the radial fundamental vibrational mode (breathing mode) was observed for all of them, allowing us to determine their breathing mode periods.

In the case of AuAg systems, the experimental normalized periods were different for alloyed and segregated AuAg coreshell nanospheres. In both cases, measurements were in quantitative agreement with predictions based on continuous elastic theory. For alloy composition, frequencies were calculated by averaging macroscopic elastic parameters (e.g., their sound velocities or fundamental elastic constants). In the case of core-shell nanostructures, predictions are based on a two material continuous elastic mechanics approach, $9,19,72$ whose previous application to a metal dielectric systems ${ }^{18}$ has been thus extended to bimetallic AuAg nanoobjects. Compar ison between experiments and theoretical predictions on alloyed and core-shell AuAg nanosystems demonstrates that the measurement of their breathing mode periods can be used to probe and discriminate their internal structures.

The same model was used for analyzing breathing mode periods of small glass embedded PtAu core-shell nanospheres, synthesized by physical methods with very low size dispersion and surfaces free of contaminant molecules. Ultrafast optical detection of their breathing mode frequencies could again be used to discriminate their internal structure (Pt@Au or Au@Pt core-shell), measured periods being in agreement with the predictions only for the expected configuration. This further confirms that a macroscopic acoustic model based on continuous mechanics with bulk material elastic constants is valid for predicting the acoustic response of particles with sizes down to the nanometer size range. This conclusion, already reported for monometallic nanospheres ${ }^{13}$ can thus be extended to bimetallic nanometric size structures. Robustness of the model was tested by FEM computation on more realistic asymmetric PtAu small size structures.

Combination of two metals at the nanoscale being a relatively unexplored subject, studying its effect on other ultrafast properties through investigation of their time resolved dynamics could also lead to a better understanding of the mixed systems. In this context, higher order harmonic modes of such systems could be detected and their composition dependence characterized by a similar experimental approach as the one presented here., ${ }^{4,88}$ Study of other dynamical properties as electron-electron and electron-lattice thermalization of bimetallic systems could also yield interesting informa tion. ${ }^{10,89,90}$ The effect of the shape of small bimetallic nanoobjects on the acoustic dynamics would similarly deserve further investigations, through the analysis of distinct vibra tional modes that could bring new insight into the effect of alloying on the elastic properties.

\section{AUTHOR INFORMATION}

\section{Corresponding Author}

*(P.M.) E mail: paolo.maioli@univ lyon1.fr.

Notes

The authors declare no competing financial interest.

\section{REFERENCES}

(1) Craighead, H. G. Nanoelectromechanical Systems. Science 2000, 290, 1532-1535.

(2) Ekinci, K. L.; Roukes, M. L. Nanoelectromechanical Systems. Rev. Sci. Instrum. 2005, 76, 061101.

(3) Del Fatti, N.; Voisin, C.; Chevy, F.; Vallée, F.; Flytzanis, C. Coherent Acoustic Mode Oscillation and Damping in Silver Nanoparticles. J. Chem. Phys. 1999, 110, 11484-11487.

(4) Voisin, C.; Del Fatti, N.; Christofilos, D.; Vallée, F. Time Resolved Investigation of the Vibrational Dynamics of Metal Nanoparticles. Appl. Surf. Sci. 2000, 164, 131-139.

(5) Ruijgrok, P. V.; Zijlstra, P.; Tchebotareva, A. L.; Orrit, M. Damping of Acoustic Vibrations of Single Gold Nanoparticles Optically Trapped in Water. Nano Lett. 2012, 12, 1063-1069.

(6) Yu, K.; Zijlstra, P.; Sader, J. E.; Xu, Q. H.; Orrit, M. Damping of Acoustic Vibrations of Immobilized Single Gold Nanorods in Different Environments. Nano Lett. 2013, 13, 2710-2716.

(7) Major, T. A.; Crut, A.; Gao, B.; Lo, S. S.; Del Fatti, N.; Vallée, F.; Hartland, G. V. Damping of the Acoustic Vibrations of a Suspended Gold Nanowire in Air and Water Environments. Phys. Chem. Chem. Phys. 2013, 15, 4169-4176.

(8) Crut, A.; Maioli, P.; Del Fatti, N.; Vallée, F. Acoustic Vibrations of Metal Nano Objects: Time Domain Investigations. Phys. Rep. 2015, $549,1-43$.

(9) Crut, A.; Maioli, P.; Del Fatti, N.; Vallée, F. Time Domain Investigation of the Acoustic Vibrations of Metal Nanoparticles: Size and Encapsulation Effects. Ultrasonics 2015, 56, 98-108.

(10) Hartland, G. V. Optical Studies of Dynamics in Noble Metal Nanostructures. Chem. Rev. 2011, 111, 3858-3887.

(11) Major, T. A.; Lo, S. S.; Yu, K.; Hartland, G. V. Time Resolved Studies of the Acoustic Vibrational Modes of Metal and Semi conductor Nano Objects. J. Phys. Chem. Lett. 2014, 5, 866-874.

(12) Krauss, T.; Wise, F. Coherent Acoustic Phonons in a Semiconductor Quantum Dot. Phys. Rev. Lett. 1997, 79, 5102-5105.

(13) Juvé, V.; Crut, A.; Maioli, P.; Pellarin, M.; Broyer, M.; Del Fatti, N.; Vallee, F. Probing Elasticity at the Nanoscale: Terahertz Acoustic Vibration of Small Metal Nanoparticles. Nano Lett. 2010, 10, 18531858.

(14) Hodak, J. H.; Henglein, A.; Hartland, G. V. Size Dependent Properties of Au Particles: Coherent Excitation and Dephasing of Acoustic Vibrational Modes. J. Chem. Phys. 1999, 111, 8613-8621.

(15) Sauceda, H. E.; Mongin, D.; Maioli, P.; Crut, A.; Pellarin, M.; Del Fatti, N.; Vallée, F.; Garzón, I. L. Vibrational Properties of Metal Nanoparticles: Atomistic Simulation and Comparison with Time Resolved Investigation. J. Phys. Chem. C 2012, 116, 25147-25156.

(16) Sauceda, H. E.; Salazar, F.; Pérez, L. A.; Garzón, I. L. Size and Shape Dependence of the Vibrational Spectrum and Low Temper ature Specific Heat of Au Nanoparticles. J. Phys. Chem. C 2013, 117, $25160-25168$. 
(17) Tlahuice Flores, A.; Whetten, R. L.; Jose Yacaman, M. Vibrational Normal Modes of Small Thiolate Protected Gold Clusters. J. Phys. Chem. C 2013, 117, 12191-12198.

(18) Mongin, D.; Juvé, V.; Maioli, P.; Crut, A.; Del Fatti, N.; Vallée, F.; Sánchez Iglesias, A.; Pastoriza Santos, I.; Liz Marzán, L. M. Acoustic Vibrations of Metal Dielectric Core Shell Nanoparticles. Nano Lett. 2011, 11, 3016-3021.

(19) Crut, A.; Juvé, V.; Mongin, D.; Maioli, P.; Del Fatti, N.; Vallée, F. Vibrations of Spherical Core Shell Nanoparticles. Phys. Rev. B 2011, 83, 205430.

(20) Guillon, C.; Langot, P.; Del Fatti, N.; Vallée, F.; Kirakosyan, A. S.; Shahbazyan, T. V.; Cardinal, T.; Treguer, M. Coherent Acoustic Vibration of Metal Nanoshells. Nano Lett. 2007, 7, 138-142.

(21) Mazurenko, D.; Shan, X.; Stiefelhagen, J.; Graf, C.; van Blaaderen, A.; Dijkhuis, J. Coherent Vibrations of Submicron Spherical Gold Shells in a Photonic Crystal. Phys. Rev. B 2007, 75, 161102.

(22) Varnavski, O.; Ramakrishna, G.; Kim, J.; Lee, D.; Goodson, T. Optically Excited Acoustic Vibrations in Quantum Sized Monolayer Protected Gold Clusters. ACS Nano 2010, 4, 3406-3412.

(23) Hodak, J. H.; Henglein, A.; Hartland, G. V. Coherent Excitation of Acoustic Breathing Modes in Bimetallic Core-Shell Nanoparticles. J. Phys. Chem. B 2000, 104, 5053-5055.

(24) Sader, J. E.; Hartland, G. V.; Mulvaney, P. Theory of Acoustic Breathing Modes of Core-Shell Nanoparticles. J. Phys. Chem. B 2002, 106, 1399-1402.

(25) Portales, H.; Saviot, L.; Duval, E.; Gaudry, M.; Cottancin, E.; Pellarin, M.; Lermé, J.; Broyer, M. Resonant Raman Scattering by Quadrupolar Vibrations of Ni Ag Core Shell Nanoparticles. Phys. Rev. B 2002, 65, 165422.

(26) Wang, L.; Kiya, A.; Okuno, Y.; Niidome, Y.; Tamai, N. Ultrafast Spectroscopy and Coherent Acoustic Phonons of Au Ag Core Shell Nanorods. J. Chem. Phys. 2011, 134, 054501.

(27) Cardinal, M. F.; Mongin, D.; Crut, A.; Maioli, P.; Rodríguez González, B.; Pérez Juste, J.; Liz Marzán, L. M.; Del Fatti, N.; Vallée, F. Acoustic Vibrations in Bimetallic Au@Pd Core-Shell Nanorods. J. Phys. Chem. Lett. 2012, 2, 613-619.

(28) Portales, H.; Saviot, L.; Duval, E.; Gaudry, M.; Cottancin, E.; Lermé, J.; Pellarin, M.; Broyer, M.; Prével, B.; Treilleux, M. Resonance and Composition Effects on the Raman Scattering from Silver Gold Alloy Clusters. Eur. Phys. J. D 2001, 16, 197-200.

(29) Adichtchev, S.; Sirotkin, S.; Bachelier, G.; Saviot, L.; Etienne, S.; Stephanidis, B.; Duval, E.; Mermet, A. High Order Vibration Modes of Bimetallic Ag Au Nanoparticles Embedded in Glass. Phys. Rev. B 2009, 79, 201402.

(30) Petrova, H.; Lin, C. H.; Hu, M.; Chen, J.; Siekkinen, A. R.; Xia, Y.; Sader, J. E.; Hartland, G. V. Vibrational Response of $\mathrm{Au} \mathrm{Ag}$ Nanoboxes and Nanocages to Ultrafast Laser Induced Heating. Nano Lett. 2007, 7, 1059-1063.

(31) Calvo, F. Influence of Size, Composition, and Chemical Order on the Vibrational Properties of Gold-Silver Nanoalloys. J. Phys. Chem. C 2011, 115, 17730-17735.

(32) Calvo, F. Correction to "Influence of Size, Composition, and Chemical Order on the Vibrational Properties of Gold-Silver Nanoalloys. J. Phys. Chem. C 2012, 116, 7607-7609.

(33) Dacosta Fernandes, B.; Spuch Calvar, M.; Baida, H.; Tréguer Delapierre, M.; Oberlé, J.; Langot, P.; Burgin, J. Acoustic Vibrations of Au Nano Bipyramids and Their Modification Under Ag Deposition: a Perspective for the Development of Nanobalances. ACS Nano 2013, 7630-7639.

(34) Perez, A.; Melinon, P.; Dupuis, V.; Bardotti, L.; Masenelli, B.; Tournus, F.; Prével, B.; Tuaillon Combes, J.; Bernstein, E.; Tamion, A.; et al. Functional Nanostructures from Clusters. Int. J. Nanotechnol. 2010, 7, 523-574.

(35) Link, S.; Wang, Z. L.; El Sayed, M. A. Alloy Formation of GoldSilver Nanoparticles and the Dependence of the Plasmon Absorption on Their Composition. J. Phys. Chem. B 1999, 103, 3529-3533.
(36) Rodríguez González, B.; Sánchez Iglesias, A.; Giersig, M.; Liz Marzán, L. M. AuAg Bimetallic Nanoparticles: Formation, Silica Coating and Selective Etching. Faraday Discuss. 2004, 125, 133-144.

(37) Kreibig, U.; Vollmer, M. Optical Properties of Metal Clusters; Springer: Berlin, 1995.

(38) Gaudry, M.; Lermé, J.; Cottancin, E.; Pellarin, M.; Vialle, J.; Broyer, M.; Prével, B.; Treilleux, M.; Mélinon, P. Optical Properties of $\left(\mathrm{Au}_{\mathrm{x}} \mathrm{Ag}_{1-\mathrm{X}}\right)_{n}$ Clusters Embedded in Alumina: Evolution with Size and Stoichiometry. Phys. Rev. B 2001, 64, 085407.

(39) Cortie, M. B.; McDonagh, A. M. Synthesis and Optical Properties of Hybrid and Alloy Plasmonic Nanoparticles. Chem. Rev. 2011, 111, 3713-3735.

(40) Ferrando, R.; Jellinek, J.; Johnston, R. L. Nanoalloys: From Theory to Applications of Alloy Clusters and Nanoparticles. Chem. Rev. 2008, 108, 845-910.

(41) Barcaro, G.; Broyer, M.; Durante, N.; Fortunelli, A.; Stener, M. Alloying Effects on the Optical Properties of $\mathrm{Ag}-\mathrm{Au}$ Nanoclusters from TDDFT Calculations. J. Phys. Chem. C 2011, 115, 24085-24091.

(42) López Lozano, X.; Mottet, C.; Weissker, H. C. Effect of Alloying on the Optical Properties of $\mathrm{Ag}-\mathrm{Au}$ Nanoparticles. J. Phys. Chem. C 2013, 117, 3062-3068.

(43) Rodríguez González, B.; Burrows, A.; Watanabe, M.; Kiely, C. J.; Liz Marzán, L. M. Multishell Bimetallic AuAg Nanoparticles: Syn thesis, Structure and Optical Properties. J. Mater. Chem. 2005, 15, $1755-1759$

(44) Benten, W.; Nilius, N.; Ernst, N.; Freund, H. J. Photon Emission Spectroscopy of Single Oxide Supported Ag Au Alloy Clusters. Phys. Rev. B 2005, 72, 045403.

(45) Baida, H.; Billaud, P.; Marhaba, S.; Christofilos, D.; Cottancin, E.; Crut, A.; Lermé, J.; Maioli, P.; Pellarin, M.; Broyer, M.; et al. Quantitative Determination of the Size Dependence of Surface Plasmon Resonance Damping in Single $\mathrm{Ag@SiO}{ }_{2}$ Nanoparticles. Nano Lett. 2009, 9, 3463-3469.

(46) Perez, A.; Melinon, P.; Dupuis, V.; Jensen, P.; Prével, B.; Tuaillon, J.; Bardotti, L.; Martet, C.; Treilleux, M.; Broyer, M.; et al. Cluster Assembled Materials: a Novel Class of Nanostructured Solids with Original Structures and Properties. J. Phys. D Appl. Phys. 1997, 30, 709-721.

(47) Alayan, R.; Arnaud, L.; Bourgey, A.; Broyer, M.; Cottancin, E.; Huntzinger, J. R.; Lermé, J.; Vialle, J. L.; Pellarin, M.; Guiraud, G. Application of a Static Quadrupole Deviator to the Deposition of Size Selected Cluster Ions from a Laser Vaporization Source. Rev. Sci. Instrum. 2004, 75, 2461-2470.

(48) Cottancin, E.; Pellarin, M. Optical Probes of the Chemical Structure in Nanoalloys. In Nanoalloys: From Fundamentals to Applications; Calvo, F., Ed.; Springer: Berlin, 2013.

(49) Yaws, C. L. Chemical Properties Handbook: Physical, Thermody namic, Environmental, Transport, Safety, and Health Related Properties for Organic and Inorganic Chemicals; McGraw Hill: New York, 1999.

(50) Henglein, A. Preparation and Optical Aborption Spectra of $\mathrm{Au}_{\text {core }} \mathrm{Pt}_{\text {shell }}$ and $\mathrm{Pt}_{\text {core }} \mathrm{Au}_{\text {shell }}$ Colloidal Nanoparticles in Aqueous Solution. J. Phys. Chem. B 2000, 104, 2201-2203.

(51) Morrow, B. H.; Striolo, A. Supported Bimetallic Pt Au Nanoparticles: Structural Features Predicted by Molecular Dynamics Simulations. Phys. Rev. B 2010, 81, 155437.

(52) Cottancin, E.; Celep, G.; Lermé, J.; Pellarin, M.; Huntzinger, J. R.; Vialle, J. L.; Broyer, M. Optical Properties of Noble Metal Clusters as a Function of the Size: Comparison Between Experiments and a Semi Quantal Theory. Theor. Chem. Acc. 2006, 116, 514-523.

(53) Belloni, J.; Mostafavi, M.; Remita, H.; Marignier, J. L.; Delcourt, M. O. Radiation Induced Synthesis of Mono and Multi Metallic Clusters and Nanocolloids. New J. Chem. 1998, 22, 1239-1255.

(54) Voisin, C.; Del Fatti, N.; Christofilos, D.; Vallée, F. Ultrafast Electron Dynamics and Optical Nonlinearities in Metal Nanoparticles. J. Phys. Chem. B 2001, 105, 2264-2280. 
(55) Voisin, C.; Christofilos, D.; Del Fatti, N.; Vallée, F.; Prével, B.; Cottancin, E.; Lermé, J.; Pellarin, M.; Broyer, M. Size Dependent Electron Electron Interactions in Metal Nanoparticles. Phys. Rev. Lett. 2000, 85, 2200-2203.

(56) Arbouet, A.; Voisin, C.; Christofilos, D.; Langot, P.; Del Fatti, N.; Vallée, F.; Lermé, J.; Celep, G.; Cottancin, E.; Gaudry, M.; et al. Electron Phonon Scattering in Metal Clusters. Phys. Rev. Lett. 2003, 90, 177401.

(57) Stoll, T.; Maioli, P.; Crut, A.; Del Fatti, N.; Vallée, F. Advances in Femto Nano Optics: Ultrafast Nonlinearity of Metal Nanoparticles. Eur. Phys. J. B 2014, 87, 260.

(58) Hartland, G. V. Coherent Vibrational Motion in Metal Particles: Determination of the Vibrational Amplitude and Excitation Mecha nism. J. Chem. Phys. 2002, 116, 8048.

(59) Tchebotareva, A. L.; Ruijgrok, P. V.; Zijlstra, P.; Orrit, M. Probing the Acoustic Vibrations of Single Metal Nanoparticles by Ultrashort Laser Pulses. Laser Photonics Rev. 2010, 4, 581-597.

(60) Juvé, V.; Scardamaglia, M.; Maioli, P.; Crut, A.; Merabia, S.; Joly, L.; Del Fatti, N.; Vallée, F. Cooling Dynamics and Thermal Interface Resistance of Glass Embedded Metal Nanoparticles. Phys. Rev. B 2009, $80,195406$.

(61) Mongin, D.; Shaviv, E.; Maioli, P.; Crut, A.; Banin, U.; Del Fatti, N.; Vallée, F. Ultrafast Photoinduced Charge Separation in Metal Semiconductor Nanohybrids. ACS Nano 2012, 6, 7034-7043.

(62) Del Fatti, N.; Bouffanais, R.; Vallée, F.; Flytzanis, C. Nonequilibrium Electron Interactions in Metal Films. Phys. Rev. Lett. 1998, 81, 922-925.

(63) Lamb, H. On the Vibrations of an Elastic Sphere. Proc. London Math. Soc. 1881, s1-13, 189-212.

(64) Dubrovskiy, V. A.; Morochnik, V. S. Nonstationary Scattering of Elastic Waves by Spherical Inclusion. Earth Phys. 1981, 17, 494-504.

(65) Wang, P.; Huang, B.; Dai, Y.; Whangbo, M. H. Plasmonic Photocatalysts: Harvesting Visible Light with Noble Metal Nano particles. Phys. Chem. Chem. Phys. 2012, 14, 9813-9825.

(66) Pelton, M.; Sader, J. E.; Burgin, J.; Liu, M.; Guyot Sionnest, P.; Gosztola, D. Damping of Acoustic Vibrations in Gold Nanoparticles. Nat. Nanotechnol. 2009, 4, 492-495.

(67) Marty, R.; Arbouet, A.; Girard, C.; Mlayah, A.; Paillard, V.; Lin, V. K.; Teo, S. L.; Tripathy, S. Damping of the Acoustic Vibrations of Individual Gold Nanoparticles. Nano Lett. 2011, 11, 3301-3306.

(68) Pelton, M.; Chakraborty, D.; Malachosky, E.; Guyot Sionnest, P.; Sader, J. E. Viscoelastic Flows in Simple Liquids Generated by Vibrating Nanostructures. Phys. Rev. Lett. 2013, 111, 244502.

(69) Gambetta, A.; Manzoni, C.; Menna, E.; Meneghetti, M.; Cerullo, G.; Lanzani, G.; Tretiak, S.; Piryatinski, A.; Saxena, A.; Martin, R. L.; et al. Real Time Observation of Nonlinear Coherent Phonon Dynamics in Single Walled Carbon Nanotubes. Nat. Phys. 2006, 2, 515-520.

(70) Bohren, C. F.; Huffman, D. R. Absorption and Scattering of Light by Small Particles; Wiley: New York, 1983.

(71) Crut, A.; Maioli, P.; Del Fatti, N.; Vallée, F. Anisotropy Effects on the Time Resolved Spectroscopy of the Acoustic Vibrations of Nanoobjects. Phys. Chem. Chem. Phys. 2009, 11, 5882-5888.

(72) Kirakosyan, A. S.; Shahbazyan, T. V. Vibrational Modes of Metal Nanoshells and Bimetallic Core Shell Nanoparticles. J. Chem. Phys. 2008, 129, 034708.

(73) Landau, L. D.; Lifshitz, E. M. Theory of Elasticity, 2nd ed.; Pergamon Press: Oxford, U.K. and New York, 1970.

(74) Ledbetter, H. Monocrystal Elastic Constants and Derived Properties of the Cubic and the Hexagonal Elements. In Handbook of Elastic Properties of Solids, Liquids, and Gases; Academic Press: New York, 2001; Vol. 2.

(75) Kaye, G. W. C.; Laby, T. H. Tables of Physical and Chemical Constants, 16th ed.; Longman: London, 1995.

(76) Bonneau, F.; Combis, P.; Rullier, J. L.; Vierne, J.; Pellin, M.; Savina, M.; Broyer, M.; Cottancin, E.; Tuaillon, J.; Pellarin, M.; et al. Study of UV Laser Interaction with Gold Nanoparticles Embedded in Silica. Appl. Phys. B: Laser Opt. 2002, 75, 803-815.
(77) Christofilos, D.; Voisin, C.; Del Fatti, N.; Vallée, F. Femtosecond Nonlinear Optical Spectroscopy of the Acoustic Vibration of Metal Nanoparticles Under High Pressure. High Press. Res. 2002, 22, 277-281.

(78) Voisin, C.; Christofilos, D.; Del Fatti, N.; Vallée, F. Environment Effect on the Acoustic Vibration of Metal Nanoparticles. Phys. B 2002, $316317,89-94$.

(79) Simmons, G.; Wang, H. Single Crystal Elastic Constants and Calculated Aggregate Properties: a Handbook, 2nd ed.; M.I.T. Press: Cambridge, MA, 1971.

(80) Chouhan, S. S.; Pagare, G.; Sanyal, S. P.; Rajagopalan, M. First Principles Study on Structural, Electronic and Elastic Properties of $\mathrm{AgX}$ and $\mathrm{AuX}(\mathrm{X}=\mathrm{Mg}, \mathrm{Sc}, \mathrm{Zn}$ and $\mathrm{Cd})$ Intermetallic Compounds. Comput. Mater. Sci. 2012, 65, 58-65.

(81) Chouhan, S. S.; Pagare, G.; Rajagopalan, M.; Sanyal, S. P. First Principles Study of Structural, Electronic, Elastic and Thermal Properties of $\mathrm{YX}(\mathrm{X}=\mathrm{Cd}, \mathrm{In}, \mathrm{Au}, \mathrm{Hg}$ and $\mathrm{Tl})$ Intermetallics. Solid State Sci. 2012, 14, 1004-1011.

(82) $\mathrm{Wu}, \mathrm{Q}$; $\mathrm{Li}$, S. Alloying Element Additions to $\mathrm{Ni}_{3} \mathrm{Al}$ : Site Preferences and Effects on Elastic Properties from First Principles Calculations. Comput. Mater. Sci. 2012, 53, 436-443.

(83) Stenuit, G.; Fahy, S. First Principles Calculations of the Mechanical and Structural Properties of $\mathrm{GaN}_{\mathrm{x}} \mathrm{As}_{1-\mathrm{x}}$ : Lattice and Elastic Constants. Phys. Rev. B 2007, 76, 035201.

(84) Zotov, N.; Ludwig, A. First Principles Calculations of the Elastic Constants of $\mathrm{Fe}-\mathrm{Pt}$ Alloys. Intermetallics 2008, 16, 113-118.

(85) Polli, D.; Lisiecki, I.; Portales, H.; Cerullo, G.; Pileni, M. P. Low Sensitivity of Acoustic Breathing Mode Frequency in Co Nanocrystals Upon Change in Nanocrystallinity. ACS Nano 2011, 5, 5785-5791.

(86) Portales, H.; Goubet, N.; Saviot, L.; Adichtchev, S.; Murray, D. B.; Mermet, A.; Duval, E.; Pileni, M. P. Probing Atomic Ordering and Multiple Twinning in Metal Nanocrystals through Their Vibrations. Proc. Natl. Acad. Sci. U.S.A. 2008, 105, 14784-14789.

(87) Ashcroft, N. W.; Mermin, N. D. Solid State Physics; Holt, Rinehart and Winston: New York, 1976.

(88) Nelet, A.; Crut, A.; Arbouet, A.; Del Fatti, N.; Vallée, F.; Portales, H.; Saviot, L.; Duval, E. Acoustic Vibrations of Metal Nanoparticles: High Order Radial Mode Detection. Appl. Surf. Sci. 2004, 226, 209-215.

(89) Hodak, J. H.; Henglein, A.; Hartland, G. V. Tuning the Spectral and Temporal Response in PtAu Core-shell Nanoparticles. J. Chem. Phys. 2001, 114, 2760-2765.

(90) Broyer, M.; Cottancin, E.; Lermé, J.; Pellarin, M.; Del Fatti, N.; Vallée, F.; Burgin, J.; Guillon, C.; Langot, P. Optical Properties and Relaxation Processes at Femtosecond Scale of Bimetallic Clusters. Faraday Discuss. 2008, 138, 137-145. 